\title{
Pediatric migraine and episodic syndromes that may be associated with migraine
}

Daniele Spiri ${ }^{1}$, Victoria Elisa Rinaldi ${ }^{2,3}$ and Luigi Titomanlio $3,4,5^{*}$

\begin{abstract}
Importance: Migraine is a common disorder and a frequent cause of medical consultation in children. Many childhood episodic syndromes have been described as common precursors of migraine.
\end{abstract}

Objective: To review current knowledge on migraine and childhood episodic syndromes, and to discuss future directions for research and clinical practice.

Findings: For most children it is difficult to describe a headache and fully verbalize symptoms such as photophobia and phonophobia that must be inferred from behaviour. Classical migraine features are rare before the age of 6 years, but some migraine-related syndromes have been described. Benign paroxysmal torticollis of infancy, benign paroxysmal vertigo of childhood, cyclic vomiting syndrome and abdominal migraine are currently classified as childhood episodic syndromes, and therefore common precursors of migraine. A strong association between infantile colic and migraine has recently been reported. There are similarities between children with episodic syndromes and children with migraine, regarding social and demographic factors, precipitating and relieving factors, and accompanying gastrointestinal, neurologic, and vasomotor features. The real pathophysiological mechanisms of migraine are not fully understood. Current data obtained through molecular and functional studies provide a complex model in which vascular and neurologic events cooperate in the pathogenesis of migraine attacks. Genetic factors causing disturbances in neuronal ion channels, make a migraineur more sensitive to multiple trigger factors that activate the nociception cascade. The expanding knowledge on migraine genetics and pathophysiology may be applicable to childhood episodic syndromes. Migraine preventive strategies are particularly important in children, and could be beneficial in childhood episodic syndromes. Nonspecific analgesics like ibuprofen and acetaminophen are widely used in pediatrics to control pain and have been found to be effective also in the treatment of acute migraine attacks. Triptans are the specific fist-line drugs for acute migraine treatment.

Conclusions and relevance: Migraine phenotype differs somewhat in the developing brain, and childhood episodic syndromes may arise before typical migraine headache. Diagnosing pediatric migraine may be difficult because of children's language and cognitive abilities. The risk of underestimating migraine in pediatric age is high. An adequate diagnosis is important to maintain a good quality of life and to avoid inappropriate therapy.

Keywords: Infantile colic, Migraine, Cyclic vomiting, Recurrent abdominal pain, Functional abdominal pain, Torticollis

\footnotetext{
* Correspondence: luigi.titomanlio@rdb.aphp.fr

${ }^{3}$ Department of Pediatric Emergency Care, APHP-Hospital Robert Debré,

Paris, France

${ }^{4}$ Pediatric Migraine and Neurovascular Diseases Unit, APHP-Hospital Robert

Debré, Paris, France

Full list of author information is available at the end of the article
}

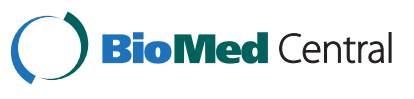

(c) 2014 Spiri et al.; licensee BioMed Central Ltd. This is an Open Access article distributed under the terms of the Creative Commons Attribution License (http://creativecommons.org/licenses/by/4.0), which permits unrestricted use, distribution, and reproduction in any medium, provided the original work is properly credited. The Creative Commons Public Domain Dedication waiver (http://creativecommons.org/publicdomain/zero/1.0/) applies to the data made available in this article, unless otherwise stated. 


\section{Background}

Headache is the most common pain condition in children and adolescents visiting a pediatrician [1] and migraine is one of the most common causes of primary headache in childhood [2]. Its prevalence increases throughout childhood, affecting 1-3\% of 3 to 7 year-olds, $4-11 \%$ of 7 to 11 year-olds, and $8-28 \%$ of teenagers (1318 years old) [3]. Migraine is a neurovascular disorder with a genetic background and several genes have been identified as being direct causal or associated agents [4]. First degree relatives of subjects with migraine have a 1.9 times higher risk of developing migraine compared to the general population $[5,6]$ and the concordance rate for migraine with aura in monozygotic twins is 34\% compared to $12 \%$ in dizygotic twins [7], suggesting the importance of genetic factors in migraine development.

Migraine is disabling at all ages; in children and adolescents it can be accompanied by significant disability, such as school absenteeism, low-quality performance and impaired emotional functioning [8]. Children with recurrent headache can suffer from depression, anxiety and often from sleep disorders and they have the tendency to feel dizzy [9]. Poor performance at school is more likely to be present in children with episodic and chronic migraine, in comparison to children without headaches. School performance is significantly influenced by severity and duration of headache attacks, by abnormal scores of mental health, and by nausea, as well as by headache frequency and use of analgesics [10].

We aimed at reviewing current knowledge and concerns on migraine and related episodic syndromes. To identify articles a literature search was carried out in PubMed and the electronic Science Direct for all studies published until July $31^{\text {st }}, 2014$. The keywords searched for were "migraine and children", "headache and children", and "episodic syndromes and migraine". Studies were included if they focused on the pediatric population, if they were published in peer reviewed journals and written in English.

\section{Migraine diagnosis and current state of clinical practice} Headache diagnosis is usually conducted on the basis of the International Headache Society (IHS) criteria. After two editions (respectively in 1988 and in 2004) [11] the latest International Classification of Headache Disorders (ICHD-III beta) is available [12].

\section{Diagnostic International Headache Society criteria for migraine without aura and migraine with aura Migraine without aura}

A. At least 5 attacks fulfilling criteria B-D

B. Headache attacks lasting 4-72 hours (untreated or unsuccessfully treated). In children, attacks may last 2-72 hours.
C. Headache has at least two of the following characteristics:

1. unilateral location (commonly bilateral in young children)

2. pulsating quality

3. moderate or severe pain intensity

4. aggravation by or causing avoidance of routine physical activity

D. During headache at least one of the following:

1. nausea and/or vomiting

2. photophobia and phonophobia

E. Not attributed to another disorder

\section{Migraine with typical aura}

A. At least 2 attacks fulfilling criteria B-D

B. Aura consisting of at least one of the following, but no motor weakness:

1. fully reversible visual symptoms including positive features (e.g., flickering lights, spots or lines) and/ or negative features (i.e., loss of vision)

2. fully reversible sensory symptoms including positive features (i.e., pins and needles) and/or negative features (i.e., numbness)

3. fully reversible dysphasic speech disturbance

C. At least two of the following:

1. homonymous visual symptoms and/or unilateral sensory symptoms

2. at least one aura symptom develops gradually over $\geq 5$ minutes and/or different aura symptoms occur in succession over $\geq 5$ minutes

3. each symptom lasts $\geq 5$ and $\leq 60$ minutes

D. Headache fulfilling criteria B-D for Migraine without aura begins during the aura or follows aura within 60 minutes

E. Not attributed to another disorder

Unlike the previous editions that were mostly based on the opinions of experts, for the latest edition there is substantial evidence available for the classification work. Already in the ICHD-II, criteria for migraine had been specifically adopted for use in children allowing a higher number of pediatric patients to be classified. The two most frequent subtypes of migraine in pediatric population are respectively migraine without aura and migraine with aura. Aura is defined as a transient focal neurological phenomenon that occurs before or during a headache. It appears gradually over several minutes and generally lasts less than 1 hour. Symptoms can be visual, sensory or motor and many children experience more than one symptom.

Migraine is the second most common cause of chronic recurrent headache in school children, with a prevalence ranging from 3.2 to $14.5 \%$ [13]. However, epidemiologic 
studies using ICHD-II demonstrated that in $27-35 \%$ of children it was not possible to perform a specific primary headache diagnosis [14-16]. Criteria for migraine diagnosis in children and adolescents are confirmed in ICHD-III beta except for duration of attacks. For the ICHD-II classification migraine may last as little as 1 hour whereas in the new classification, attacks may last from 2 to 72 hours (instead of a minimum of 4 hours in adults): the evidence for untreated migraine with a duration inferior than 2 hours in children has not been substantiated.

The younger the child is, the more atypical the symptoms are. Migraine in preschool children may lack throbbing characteristics, unilaterality and full-blown autonomic symptoms [9] but its paroxysmal and periodic occurrence is observed as the outstanding feature in all migraine manifestations at this age [17]. Children often experience a bilateral pain, usually in frontal or temporal regions, poorly defined and invariably accompanied by pallor, nausea and vomiting. The unilateral pain, typically referred by adults, usually emerges in late adolescence or early adult life. Occipital headache is not common in children, in which case a possible organic pathology should be suspected. Pain quality is different to that of adults because it is often reported as constrictiveoppressive and for most children it is difficult to describe a headache using words like "throbbing" or to fully verbalize symptoms such as photophobia and phonophobia that must be inferred from behaviour [18]. Cranial autonomic symptoms, mainly ocular and nasal (lacrimation, conjunctival injection, nasal congestion, rhinorrhoea), are frequently found in pediatric migraine, often leading to a misdiagnosis of sinus headache and delaying appropriate migraine therapy [19].

In children, migraine with aura is less frequent than migraine without aura. The most common aura symptoms in children are visual and sensorial disorders. Visual aura is typically referred as a "fortification spectrum" characterized by zigzag lines close to the fixation point that then gradually expand assuming the appearance of a convex shape displaced laterally and twinkling. Vision becomes increasingly blurred and children can experience transient hemianopsia or a complete transient unilateral blindness (amaurosis fugax). Sensorial aura is often characterized by unilateral paresthesia, hemiparesis and dysphasia. Children typically describe many small pinpricks that slowly move from the place of origin to wider regions as the arm, the leg or the face.

During the last two decades, modifications of ICHD criteria permitted to improve sensitivity of migraine diagnosis in children up to $84.4 \%[20,21]$ but studies demonstrate that there still are deficiencies in fully recognizing pediatric headache and Ballottin demonstrated that the ICHD-II criteria are poorly applicable to children below the age of 6 years [22]. Further studies are needed to define the applicability of ICHD-III criteria in the pediatric population and in order to develop alternative and more specific criteria for children. A recent study conducted by De Carlo found that $34.6 \%$ of pediatric migraine patients have osmophobia and when this symptom was utilized in the diagnostic process as an additional associated symptom, there was an increase in the percentage of subjects with a migraine diagnosis [23].

\section{Migraine pathogenetic hypothesis}

Eight genes have been so far identified as being associated with common migraine (i.e. with and without aura) [24,25]. MTDH, LRP1, PRDM16, MEF2D, ASTN2, and PHACTR1 are involved in neuronal and glutamatergic pathways; TGFBR is responsible for the maintenance of vascular integrity and function whereas TRPM8 is involved in pain signalling pathways [26]. Many advances in the understanding of migraine pathophysiology have been possible through to the study of the rare autosominal dominant Familial hemiplegic migraine (FHM). Gene mutations in membrane ion channel transport proteins, including CACNA1A (P/Q-type voltage-gated calcium channel), ATP1A2 (sodium-potassium ATPase), SCN1A (voltage-gated sodium channel), and PRRT2 (proline-rich transmembrane protein 2) lead to FHM. More recently, mutations in SLC4A4 [27], encoding the $\mathrm{Na}^{+}-\mathrm{HCO}_{3}{ }^{-}$ cotransporter NBCe1, have been identified [28]. Multiple conventional and advanced MRI techniques including susceptibility weighted imaging (SWI) play a key role during an Hemiplegic Migraine attack to exclude acute arterial ischemic stroke; the transient unilateral motor weakness that characterizes this rare type of migraine usually lasts for a few hours and neuroimaging abnormalities completely resolve within $24 \mathrm{hrs}$ after the attack onset [29].

The real pathophysiological mechanisms of migraine are not fully understood. For decades, the throbbing pain during migraine headache was thought to originate from dilated cranial arteries: unilateral stimulation of extra cranial and intracranial arteries was in fact associated with ipsilateral head pain [30]. During the past two decades the focus on this vascular hypothesis has diminished and neuronal mechanisms have been suggested as generators of migraine headache, without abnormal activation of perivascular sensory fibers [31]. More recently, current molecular and functional studies, conducted using PET, intracarotid SPECT (Single-Photon Emission Computed Tomography), MRA (magnetic resonance angiography), functional MRI and TMS (Transcranial Magnetic Stimulation), allowed to formulate a complex theory in which vascular and neurologic events cooperate in the pathogenesis of migraine attacks without aura [32]. Afferent innervations of intracranial blood vessels, forming the Trigemino-Vascular System (TVS), are the essential substrate for migraine pain in this intricate 
network [33] (Figure 1). Specific environmental triggers are supposed to initiate the neuronal excitation that leads to clinical manifestations in patients with a genetic vulnerability to migraine. Migraine-specific triggers, as foods containing vasoactive amines (e.g.: tyramine and phenylethylamine), hormonal fluctuation, psychological and environmental triggers as stress, worse mood [34], anxiety, fatigue, sleep deprivation, light, and rapid temperature changes, induce the activation of trigeminal nerve sensory fibers, which innervate intracranial blood vessels, by dilatation of cranial blood vessels. However, Amin in a recent study conducted using MRA during spontaneous unilateral migraine attacks, demonstrates that migraine pain is not accompanied by extracranial arterial dilatation but by only slight intracranial dilatation [35].

Therefore, the initial events that lead to the activation of nociception cascade are still not entirely clear. Brainstem network activation determines the release of vasoactive peptides such as CGRP (calcitonin gene-related peptide) and substance $P$ from trigeminal fibers, inducing vasodilation and neurogenic inflammation [36]. This inflammation increases the trigeminal sensory fibers activation and perpetuates the release of vasoactive peptides (sustaining the transmission of pain impulses to the brain) over a time span of hours to days in correspondence with the duration of a typical migraine episode. The cortical spreading depression (CSD) theory is thought to explain generation of migraine attacks with aura. Transcranial magnetic stimulation and functional MRI studies have shown that at baseline, migraneurs have a state of neuronal hyperexcitability in their cerebral cortex, especially in the occipital region. This suggests that the initial phase of a migraine attack with aura is a wave of cortical spreading depression which is associated with the suppression of spontaneous EEG activity and regional oligemia. CSD begins in the occipital region and moving anteriorly, stops at the central sulcus, and then spreads ventrally to the meningeal trigeminal fibers. Once the CSD occurs, $\mathrm{H}+$ and $\mathrm{K}+$ diffuse to the pia mater and activate meningeal nociceptors (C-fibers) which release pro-inflammatory agents after TVS activation [37].

Recent studies have suggested that some types of migraine may be related to a mitochondrial dysfunction [38]. Biochemical evidence supporting this relationship consists in the fact that abnormal mitochondrial function determines a high intracellular penetration of calcium, an excessive production of free radicals and a deficient oxidative phosphorylation which ultimately causes energy failure in neurons and astrocytes. These events can trigger migraine mechanisms ultimately causing CSD. Further studies are required to investigate a possible relationship between mtDNA and migraine. Current data therefore provide a complex model in which genetic factors, causing disturbances in neuronal

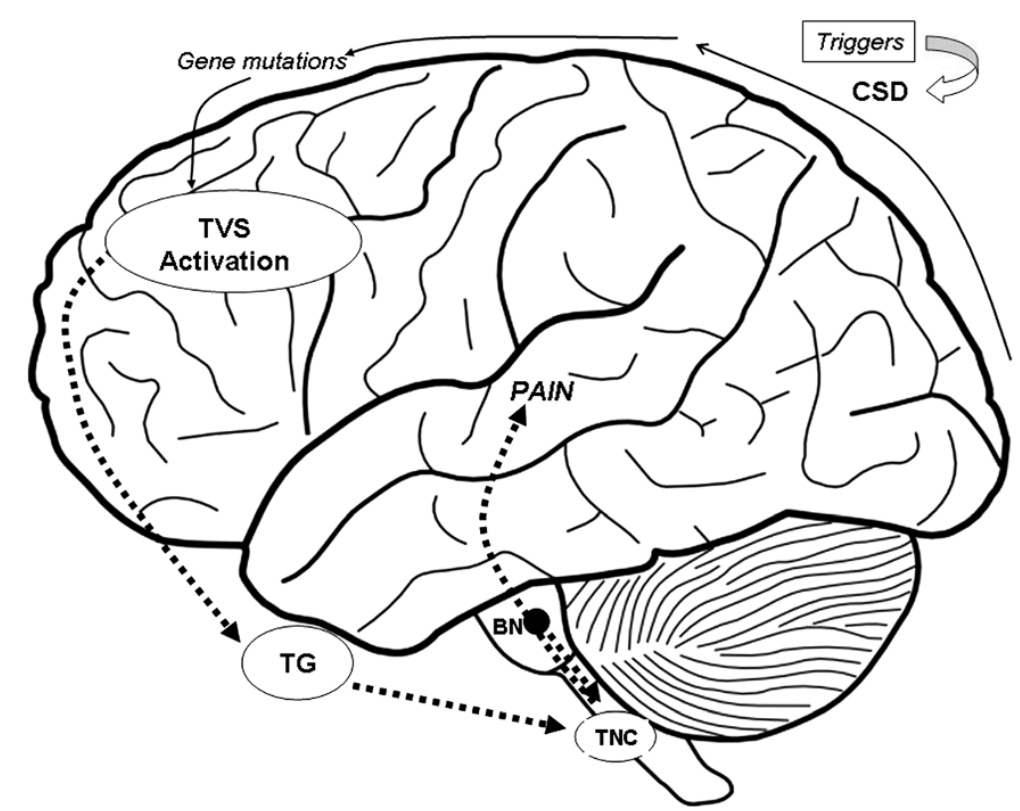

Figure 1 Migraine pain generation. Migraine triggers initiate the neuronal excitation that leads to clinical manifestations in children with a genetic vulnerability to migraine. Cortical spreading depression (CSD) triggers plasma protein extravasation from cerebral blood vessels, which in turn activates trigeminal (TG) afferents within the trigemino-vascular system (TVS). Gene mutations could reduce the threshold for firing of TG neurons. Signals are transduced to the trigeminal nucleus caudalis (TNC), which receives modulatory inputs from other brainstem nuclei (BN), such as the periaqueductal gray, the locus coeruleus and the raphe. The TNC projects to rostral brain areas, where the perception of pain is generated. 
ion channels, make a migraineur more sensitive to multiple trigger factors. The generation of migraine pain is probably a consequence of multiple pathophysiological changes in meningeal tissues, TG (Trigeminal Ganglion), trigeminal brainstem nuclei and descending inhibitory systems that are still not fully clarified and are worth further studies. The result is an activation of the brainstem which is the principal vascular tone regulating and nociceptive processing center. Activation of the brainstem also regulates the nociceptive transition to higher structures of the central nervous system (CNS), as the thalamus and the cortex [39].

\section{Treatment of migraine}

An appropriate migraine management requires filling in a diary for at least one month in order to collect more detailed information on headache characteristics and associated signs.

Migraine preventive strategies are particularly important in children, and could be beneficial in childhood episodic syndromes. Prevention of migraine attacks includes trigger management and adequate pharmacologic treatments, when needed. Frequent migraine triggers, such as physical and mental stress, school problems, irregular and unhealthy lifestyle habits [40] can be removed or modified. A correct lifestyle with appropriate nutritional and sleeping habits and regular physical activity are the first steps to achieve a high quality migraine therapy. Distraction techniques, relaxation and biofeedback are also valuable tools that pediatricians must take into account in managing migraine [41-44].

Acute pharmacological treatment consists in using drugs only during a migraine attack. Its goal is to completely eliminate pain and related symptoms. Nonspecific analgesics like ibuprofen and acetaminophen are widely used in pediatrics in order to control pain and have been studied in randomized, double-blind, placebocontrolled trials and found to be effective also in the treatment of acute migraine attacks $[45,46]$. Triptans are the specific fist-line drugs for acute migraine treatment $[47,48]$. Although nasal spray sumatriptan [49-51] and zolmitriptan [52] have positive randomized trials in children, only almotriptan [53] (in adolescents aged 12-17 years) and rizatriptan [54] (for 6-17 years olds) are now FDA-approved for pediatric use. Generally ergot alkaloid dihydroergotamine [55], dopamine receptor antagonists [56] and opioids are not considered first-line treatment of acute migraine in children and adolescents because of their potential side-effects and, especially regarding opioids, because of their association with the development of chronic migraine and medication overuse headache $[57,58]$.

Sheridan et al. [59] recently described the variability in diagnostic testing and treatment of headaches in children presenting to the emergency department and found that despite evidence based clinical guidelines, a large number of children with migraine continued to receive opioids as acute treatment.

Pharmacologic preventive treatment is generally proposed when migraine attacks occur once a week or whenever the attacks are particularly long and debilitating [60]. Among migraine preventives, topiramate [61-63], flunarizine [64], amitriptyline $[65,66]$ and divalproex sodium $[67,68]$ have evidence of efficacy and safety supporting their use in children.

\section{Current state of clinical practice and diagnosis of childhood episodic syndromes}

A range of symptoms and signs (such as vertigo, torticollis, visual and sensorimotor disturbances, anorexia, recurrent abdominal pain, nausea and vomiting, motion sickness, sleep and behavioural disorders) may occur in children in the absence of headache and may precede the development of typical migraine manifestations by several years $[69,70]$.

Benign paroxysmal torticollis, benign paroxysmal vertigo, cyclic vomiting syndrome and abdominal migraine are defined as "episodic syndromes that may be associated with migraine" in ICHD-III beta [12]. In 2001, Jan documented a relationship between infantile colic and migraine [71]. His data suggested that children with migraine were more likely to have a personal history of infantile colic and a family history of infantile colic or migraine in any of the first-degree relatives. Children with a history of infantile colic were also more likely to have a positive family history for migraine. Jan supposed that pain and crying in some genetically predisposed infants could represent a form of infantile migraine with an age specific expression. We recently confirmed the association between migraine and infantile colic with a multicenter case-control study [72], suggesting that colic may represent one of the earliest clinical manifestations of migraine such as the episodic syndromes included in ICHD-III beta [18] (Figure 2). Paroxysmal tonic up gaze [73], recurrent abdominal pain [74], motion sickness [75], recurrent limb pain [76], and parasomnias [77] are not clearly associated with migraine and are not yet universally accepted as precursors of migraine.

Childhood episodic syndromes are characterized by reversible and stereotyped attacks, with a periodic occurrence. Children are healthy and neurologically normal between attacks [78-80]. There are strong similarities between children with episodic syndromes and children with migraine, regarding social and demographic factors, precipitating and relieving factors, and accompanying gastrointestinal, neurologic, and vasomotor features [17]. Children with episodic syndromes often have a positive family history for migraine and those with earlier-onset episodic syndromes may eventually develop migraine in 


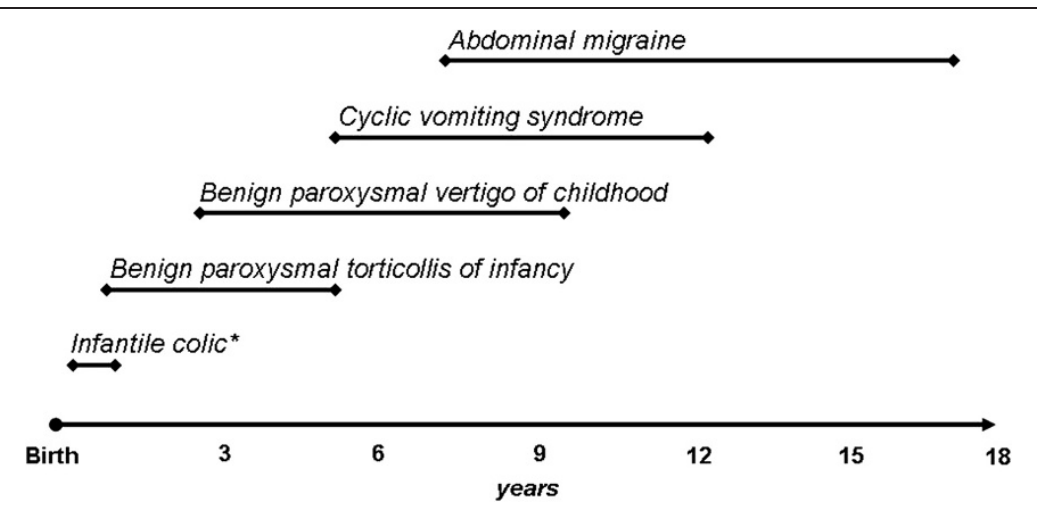

Figure 2 Age-related expression of childhood episodic syndromes common precursors of migraine. * $=$ infantile colic is actually considered as an episodic syndrome that may be associated with migraine.

adolescence or adult age [81]. The clinical improvement observed with migraine-specific drugs (triptans) further confirms the association of episodic syndromes with migraine. Diagnosis of childhood episodic syndrome is one of exclusion and involves a careful anamnesis, physical examination and appropriate neurodiagnostic studies to exclude other discernable causes as epilepsy, metabolic disorders, ischemic events or psychological disorders.

\section{Infant colic}

Recent research suggests that infantile colic may be a childhood episodic syndrome [72,80]. Infantile colic affects $5-19 \%$ of babies during their first months of life and, according to Wessel criteria, it is characterized by inconsolable crying and fussing for more than 3 hours per day, more than 3 days per week and for more than 3 weeks in an otherwise healthy and well-fed infant [82-84].

Benign paroxysmal torticollis of infancy (ICHD III beta 1.6.3) Benign paroxysmal torticollis is a rare paroxismal dyskinesia that appears commonly around the age of 2 to 8 months. It is characterized by recurrent and stereotyped attacks of abnormal inclination or rotation of the head, occasionally accompanied by vomiting and ataxia. Torticollis is secondary to cervical dystonia although it may occur in association with other dystonic features such as truncal and pelvic asymmetrical posturing [78]. During an episode it is possible to observe pallor, photophobia, ataxia, drowsiness and headache which resemble migraine features. The episodes often last from several hours to days, and have a spontaneous resolution. Typically, the attacks frequency and duration decline as the child grows older with a definitive resolution at the age of 5 years [85].

Benign paroxysmal vertigo of childhood (ICHD III beta 1.6.2) Benign paroxysmal vertigo occurs as a sudden attack of unexplained fright accompanied by balance troubles or even falls [86]. The onset is characterized by a sudden expression of anxiety and fear followed by attempting to grasp a person or any other support standing nearby. Autonomic signs such as dizziness, nausea, pallor, perspiration, photophobia and phonophobia may accompany vertigo. Vomiting and nystagmus are common. The episodes, lasting generally less than 5 minutes, are never associated with loss of consciousness [87]. The onset is between the age of 2 to 4 years and the frequency of attacks varies from once a day to once every 1-3 months [88]. Typically, children suffering from benign paroxysmal vertigo have a positive family history for migraine and a positive family and personal history for motion sickness. Some patients may develop other childhood episodic syndromes such as cyclic vomiting or recurrent abdominal pain [89]. Some authors suggest that benign paroxysmal vertigo may constitute an early-onset variant of basilartype migraine [90].

\section{Cyclic vomiting syndrome (ICHD III beta 1.6.1.1)}

This syndrome is characterized by recurrent and selflimited episodes of severe nausea and vomiting, interspersed with symptom-free periods. Affected children usually experience a stereotypical pattern of events in which a prodromal phase is followed by an emetic and a recovery phase [91]. During the prodromal phase, lasting about 1.5 hours, children experience an impending episode characterized by worsening nausea and a dramatic autonomic dysfunction with decreased muscle tone, pallor, lethargy and apathy. This clinical picture evolves into emetic phase in which vomiting is typically intense, often bilious, and accompanied by persistent nausea, anorexia, retching, increased salivation, abdominal pain, headache, pallor, photophobia and phonophobia. This phase lasts an average of 24 hours before the beginning of the recovery phase characterized by remission of nausea and resumption of normal appetite, of oral intake and of a baseline clinical status [92]. 
The onset of cyclic vomiting syndrome occurs generally before the age of 6 years and the frequency of episodes varies between 3 and 12 per year [93]. The median age for resolution of vomiting episodes is 10 years and $75 \%$ of affected children will develop migraine by the age of 18 years [94].

\section{Abdominal migraine (ICHD III beta 1.6.1.2)}

Abdominal migraine is characterized by recurrent, acute-onset abdominal pain lasting for hours or days and accompanied by dysautonomic signs such as pallor, dark shadows under the eyes, flushing, anorexia and vomiting [95]. Affected children experience a dull or colicky pain generally localized in periumbelical region. During the inter-episodic period children are completely healthy [96]. The onset of abdominal migraine occurs at the age of 7 years with a peak of prevalence at 10 years of age [97]. Some studies suggest that abdominal migraine could persist into adult life and $70 \%$ of affected children develop migraine as they grow older. There are similarities between affected children and children with migraine regarding demographic, social, clinical and familial features. Moreover, children with abdominal migraine manifest similar triggering events such as psychological stress, physical exhaustion and motion sickness [93]. Sometimes, a preceding aura occurs with visual disturbance, flashing lights, numbness or a tingling sensation, slurred speech or muscle weakness.

\section{Childhood episodic syndromes pathogenetic hypothesis}

The expanding knowledge on migraine genetics and pathophysiology may be applicable to childhood episodic syndromes. According to the fact that both gut and nervous system are derived from the same embryologic tissues and that the enteric nervous system and the CNS exert direct effects on each other [98], it has been hypothesized that pathogenesis of abdominal migraine consists in an increased arousal in the CNS in response to triggers, thus releasing neuropeptides and neurotrasmitters that lead to dysregulation of the gastrointestinal system. This could also explain the recent demonstrated association between infantile colic and migraine. We supposed that infants with colic experience a sensitization of the perivascular nerve terminals in the gut, as happens in the brain during a migraine attack [72]. The potential role of molecules as CGRP, involved in modulation of sensory activity in both the brain and the gut, remains to be elucidated [99]. A disrupted sleep pattern might be a trigger for colic symptoms, as it is often observed in patients with migraine [100]. Cyclic vomiting syndrome is also believed to be a brain-gut disorder involving neuroendocrine pathways in genetically predisposed individuals $[101,102]$. The same dysregulated pathways may be involved in symptoms accompanying migraine attacks as nausea and vomiting [103].

Mutations in the CACNA1A and PRRT2 genes, which are associated with FHM, have been found in some patients with benign paroxysmal torticollis and benign paroxysmal vertigo [85,104], thus confirming their link to migraine. Transitory vascular disturbances in cerebellar cortex, where CACNA1A is abundantly expressed, were demonstrated in temporal cortex and the vestibular nuclei respectively during episodes of torticollis and vertigo [105].

\section{Treatment of episodic syndromes}

No specific treatment exists for infant colic. Positive results have been obtained by decreasing the infant's level of stimulation during acute episodes $[106,67]$ as it is observed in migraine. There are no known effective treatments for both benign paroxysmal torticollis and vertigo. Antiemetics could be considered in the acute phase if there is significant vomiting. Acute treatment of cyclic vomiting syndrome typically consists in rehydration and antiemetics [18]. A favourable response to subcutaneous and nasal spray sumatriptan has been reported [68] and represents another argument in favour of a relationship with migraine. Abdominal migraine generally responds to triptans [106]. Preventive treatment with flunarizine can be considered if attacks are frequent or long-lasting [107].

\section{Remaining concerns and future directions for migraine and related syndromes}

ICHD criteria are useful to simplify and standardize diagnostic approach to primary headache, and represent the gold standard for diagnosing migraine and childhood episodic syndromes. However, applying diagnostic criteria to children can be difficult because the course of the disease and the description of the acute events are often inaccurate, especially regarding parameters like duration, intensity and localization [108]. The ICHD-II criteria (and probably the new ICHD-III beta criteria too) are still poorly applicable to children under the age of 6 years [22] and it is likely that infantile colic and osmophobia will be considered respectively as a precursor and an alternative symptom of migraine in future revisions, because of the strong association observed. Modification of the criteria in order to include bilateral headache, shorter duration of the attacks, nausea and/or vomiting associated with at least two out of five other associated symptoms (photophobia, phonophobia, difficulty in thinking, light-headedness or fatigue) which must be derived form behavior, in addition to the usual description of moderate to severe pain of a throbbing or pulsating nature, worsening or limiting physical activity, improved accuracy of migraine diagnosis in children $[20,22]$. Indeed, when migraine is under-diagnosed the 
risk is of an immoderate use of analgesics: it is demonstrated that $42.5 \%$ of subjects with headache use medicines. $68.2 \%$ of these reported that medicines for headache were always available at home, and $22.2 \%$ were allowed to use these without asking for permission [109]. Since drug overuse makes treatment of headache difficult to deal, it is important to supervise this condition, which is particularly common in adolescents [110].

Significant progresses in molecular genetics have advanced our understanding of the genetic basis of migraine and related syndromes, also revealing promising treatment targets for future drug development. Genetic findings have revealed ion channels and transporter mutations as causative of migraine [111], which seems to be related to ionic disturbances with a resultant altered excitability of certain areas of the brain and an age-specific phenotype.

New technological strategies such as next-generation sequencing, may aid in the identification of FHM related genes and promote the research for the missing heritability of common migraine [112]. These platforms are able to generate more sequence data; they are less expensive and could help us in finding answers to how migraine attacks start [113] and what the links with childhood episodic syndromes are. It is likely that the study of epigenetic mechanisms (i.e. DNA methylation and post-translational modifications of histone proteins), which affect gene expression and cellular responses to environmental signals, may explain in the next future how non-genetic triggers may modulate attack frequency of migraine [114]. It is realistic to imagine that further studies may reveal tractable drug targets, and this will also help in the understanding of migraine pathogenic process, which is essential for a rational development of effective treatments.

Development of primary headache may be furthered by environmental conditions [115-117]. A child's environment includes home, school, and community and all of these areas may have profound influences on headache [118]. An association between migraine, parentalreported emotional problems and self-reported anxiety suggests that emotional factors may be early contributors in the pathogenesis of pediatric headache $[119,120]$.

Children with frequents attacks of paroxysmal vertigo or paroxysmal torticollis are very limited in daytime activities and this also influences familial organisation. The same is true for cyclic vomiting attacks, during which children are often hospitalized for intravenous rehydration, and for abdominal migraine, which attacks are often debilitating and can last for days. When migraine attacks are too frequent, too long, or too painful, children's quality of life can be affected. Therefore, it could be useful to assess the level of life quality by validated scores [121], not only in migraine but also in episodic syndromes, when possible. Performing a score during the initial diagnostic assessment can also help in monitoring the therapeutic response: changes in score are an index of the adequacy of undertaken treatment. Several studies have helped to define the relationship between psychiatric and psychological co morbidities in children suffering from migraine and cyclic vomiting. Whether these comorbidities are triggers or the consequence of a chronic invalidating condition should be proven further.

\section{Conclusions}

Pediatricians are frequently involved in the care of children and adolescents with headache.

Diagnosing pediatric migraine may be difficult because of children's language and cognitive abilities and it is frequently necessary to detect migrainous symptoms from behaviour. The risk of underestimating the real prevalence of migraine in pediatric age is high and an adequate diagnosis is important to limit uncomfortable situations in school, social and family settings, to maintain a good quality of life and to avoid inappropriate therapy.

Migraine phenotype differs somewhat in the developing brain, and childhood episodic syndromes may arise before typical migraine headache. Being familiar with the characteristics and evolution of childhood episodic syndromes may help pediatricians make correct diagnosis and give adequate treatments, avoiding unnecessary investigations.

\section{Abbreviations}

CGRP: Calcitonin-gene-related peptide; CNS: Central nervous system; CSD: Cortical spreading depression; EEG: Electroencephalogram; FDA: Food and Drugs Administration; FHM: Familial hemiplegic migraine; ICHD: Criteria of the International Classification of Headache Disorders; MRI: Magnetic resonance imaging; PET: Positron emission tomography; SPECT: Single-photon emission computed tomography; MRA: Magnetic resonance angiography; TG: Trigeminal Ganglion; TMS: Transcranial magnetic stimulation;

TVS: Trigemino-vascular system

\section{Competing interests}

All authors declare: no support from any organisation for the submitted work, no financial relationships with any organisations that might have an interest in the submitted work in the previous three years, no other relationships or activities that could appear to have influenced the submitted work.

\section{Authors' contributions}

All co-authors have seen and agree with the contents of the manuscript. All authors read and approved the final manuscript.

\section{Financial disclosure}

The authors have no financial relationships relevant to this article to disclose. The Corresponding Author has the right to grant on behalf of all authors and does grant on behalf of all authors, a worldwide licence to the

Publishers and its licensees in perpetuity, in all forms, formats and media (whether known now or created in the future), to 1) publish, reproduce, distribute, display and store the Contribution, 2) translate the Contribution into other languages, create adaptations, reprints, include within collections and create summaries, extracts and/or, abstracts of the Contribution, 3) create any other derivative work(s) based on the Contribution, 4) to exploit all subsidiary rights in the Contribution, 5) the inclusion of electronic links from the Contribution to third party material where-ever it may be located; and, 6) licence any third party to do any or all of the above". 


\section{Author details}

'Department of Pediatrics, Luigi Sacco Hospital, Università degli Studi di Milano, Milan, Italy. ${ }^{2}$ Department of Pediatrics, Università degli Studi di Perugia, Perugia, Italy. ${ }^{3}$ Department of Pediatric Emergency Care, APHP-Hospital Robert Debré, Paris, France. ${ }^{4}$ Pediatric Migraine and Neurovascular Diseases Unit, APHP-Hospital Robert Debré, Paris, France. ${ }^{5}$ Pediatric Emergency Department, Robert Debré University Hospital, 48, Bld Sérurier, Paris 75019, France.

Received: 1 September 2014 Accepted: 7 November 2014

Published online: 19 November 2014

\section{References}

1. Bhatia A, Brennan L, Abrahams M, Gilder F: Chronic pain in children in the UK: a survey of pain clinicians and general practitioners. Pediatr Anaesth 2008, 18:957-966.

2. Chu ML, Shinnar S: Headaches in children younger than 7 years of age. Arch Neurol 1992, 49:79-82

3. Oakley CB, Kossoff EH: Migraine and Epilepsy in the Pediatric Population Current Pain Headache Rep 2014, 18:402.

4. Hershey AD: Pediatric headache: update on recent research. Headache 2012, 52:327-332.

5. Russell MB, Olesen J: Increased familial risk and evidence of genetic factor in migraine. BMJ 1995, 311:541-544.

6. Bener A, Uduman SA, Qassimi EM, Khalaily G, Sztriha L, Kilpelainen H, Obineche E: Genetic and environmental factors associated with migraine in schoolchildren. Headache 2000, 40:152-157.

7. Ulrich V, Gervil M, Kyvik KO, Olesen J, Russell MB: Evidence of a genetic factor in migraine with aura: a population-based Danish twin study. Ann Neurol 1999, 45:242-246.

8. Rossi P, Di Lorenzo G, Malpezzi MG, Di Lorenzo C, Cesarino F, Faroni J, Siracusano A, Troisi A: Depressive symptoms and insecure attachment as predictors of disability in a clinical population of patients with episodic and chronic migraine. Headache 2005, 45:561-570.

9. Jacobs $\mathrm{H}$, Gladstein J: Pediatric headache: a clinical review. Headache 2012, 52:333-339.

10. Arruda MA, Bigal ME: Migraine and migraine subtypes in preadolescent children: association with school performance. Neurology 2012, 79:1881-1888

11. The International Headache Society: The International Classification of Headache Disorders: 2nd edition. Cephalalgia 2004, 24(Suppl 1):9-160.

12. The International Headache Society: The International Classification of Headache Disorders, 3rd edition (beta version). Cephalalgia 2013, 33:629-808.

13. Ozge A, Termine C, Antonaci F, Natriashvili S, Guidetti V, Wober-Bingol C: Overview of diagnosis and management of pediatric headache. Part I: diagnosis. J Headache Pain 2011, 12:13-23.

14. Kroner-Herwig B, Heinrich M, Morris L: Headache in German children and adolescents: a population-based epidemiological study. Cephalalgia 2007, 27:519-527.

15. Heinrich M, Morris L, Kroner-Herwig B: Self-report of headache in children and adolescents in Germany: possibilities and confines of questionnaire data for headache classification. Cephalalgia 2009, 29:864-872.

16. Gassmann J, Morris L, Heinrich M, Kroner-Herwig B: One-year course of pediatric headache in children and adolescents aged 8-15 years. Cephalalgia 2008, 28:1154-1162.

17. Cuvellier JC, Lepine A: Childhood periodic syndromes. Pediatr Neurol 2010, 42:1-11.

18. Gelfand AA: Migraine and childhood periodic syndromes in children and adolescents. Curr Opin Neurol 2013, 26:262-268.

19. Gelfand AA, Reider AC, Goadsby PJ: Cranial autonomic symptoms in pediatric migraine are the rule, not the exception. Neurology 2013, 81:431-436.

20. Wober-Bingol C, Wober C, Karwautz A, Auterith A, Serim M, Zebenholzer K, Aydinkoc K, Kienbacher C, Wanner C, Wessely P: Clinical features of migraine: a cross-sectional study in patients aged three to sixty-nine. Cephalalgia 2004, 24:12-17.

21. Hershey AD, Winner P, Kabbouche MA, Gladstein J, Yonker M, Lewis D, Pearlman E, Linder SL, Rothner AD, Powers SW: Use of the ICHD-II criteria in the diagnosis of pediatric migraine. Headache 2005, 45:1288-1297.
22. Balottin U, Termine C, Nicoli F, Quadrelli M, Ferrari-Ginevra O, Lanzi G: Idiopathic headache in children under six years of age: a follow-up study. Headache 2005, 45:705-715.

23. De Carlo D, Dal Zotto L, Perissinotto E, Gallo L, Gatta M, Balottin U, Mazzotta G, Moscato D, Raieli V, Rossi LN, Sangermani R, Soriani S, Termine C, Tozzi E, Vecchio A, Zanchin G, Battistella PA: Osmophobia in migraine classification: a multicentre study in juvenile patients. Cephalalgia 2010, 30:1486-1494.

24. Anttila V, Stefansson H, Kallela M, Todt U, Terwindt GM, Calafato MS, Nyholt DR, Dimas AS, Freilinger T, Müller-Myhsok B, Artto V, Inouye M, Alakurtti $\mathrm{K}$, Kaunisto MA, Hämäläinen E, de Vries B, Stam AH, Weller CM, Heinze A, Heinze-Kuhn K, Goebel I, Borck G, Göbel H, Steinberg S, Wolf C, Björnsson A, Gudmundsson G, Kirchmann M, Hauge A, Werge T, et al: Genome-wide association study of migraine implicates a common susceptibility variant on 8q22.1. Nat Genet 2010, 42:869-873.

25. Chasman DI, Schurks M, Anttila V, De Vries B, Schminke U, Launer LJ, Terwindt GM, van den Maagdenberg AM, Fendrich K, Volzke H, Ernst F, Griffiths LR, Buring JE, Kallela M, Freilinger T, Kubisch C, Ridker PM, Palotie A, Ferrari MD, Hoffmann W, Zee RY, Kurth T: Genome-wide association study reveals three susceptibility loci for common migraine in the general population. Nat Genet 2011, 43:695-698.

26. Ferrari MD: Headache: the changing migraine brain. Lancet Neurol 2013, $12: 6-8$.

27. Suzuki M, Van Paesschen W, Stalmans I, Horita S, Yamada H, Bergmans BA, Legius E, Riant F, De Jonghe P, Li Y, Sekine T, Igarashi T, Fujimoto I, Mikoshiba K, Shimadzu M, Shiohara M, Braverman N, Al-Gazali L, Fujita T, Seki G: Defective membrane expression of the $\mathrm{Na}(+)-\mathrm{HCO}(3)(-)$ cotransporter NBCe1 is associated with familial migraine. Proc Natl Acad Sci U S A 2010, 107:15963-15968.

28. Vecchia D, Pietrobon D: Migraine: a disorder of brain excitatory-inhibitory balance? Trends Neurosci 2012, 35:507-520.

29. Bosemani T, Burton VJ, Felling RJ, Leigh R, Oakley C, Poretti A, Huisman TA Pediatric hemiplegic migraine: Role of multiple MRI techniques in evaluation of reversible hypoperfusion. Cephalalgia 2013, 34:311-315.

30. Tunis MM, Wolff HG: Studies on headache; long-term observations of the reactivity of the cranial arteries in subjects with vascular headache of the migraine type. AMA Arch Neurol Psychiatry 1953, 70:551-557.

31. Goadsby PJ: The vascular theory of migraine-a great story wrecked by the facts. Brain 2009, 132:6-7.

32. Edvinsson L, Uddman R: Neurobiology in primary headaches. Brain Res Brain Res Rev 2005, 48:438-456.

33. Messlinger K: Migraine: where and how does the pain originate? Exp Brain Res 2009, 196:179-193.

34. Karlson CW, Litzenburg CC, Sampilo ML, Rapoff MA, Connelly M, Bickel JL, Hershey AD, Powers SW: Relationship Between Daily Mood and Migraine in Children. Headache 2013, 53:1624-1634.

35. Amin FM, Asghar MS, Hougaard A, Hansen AE, Larsen VA, De Koning PJ, Larsson HB, Olesen J, Ashina M: Magnetic resonance angiography of intracranial and extracranial arteries in patients with spontaneous migraine without aura: a cross-sectional study. Lancet Neurol 2013, 12:454-461

36. Durham PL: Calcitonin gene-related peptide (CGRP) and migraine. Headache 2006, 46(Suppl 1):S3-S8.

37. Ayata C: Cortical spreading depression triggers migraine attack: pro Headache 2010, 50:725-730.

38. Yorns WR Jr, Hardison $\mathrm{HH}$ : Mitochondrial dysfunction in migraine. Semin Pediatr Neurol 2013, 20:188-193.

39. Goadsby PJ, Edvinsson L, Ekman R: Vasoactive peptide release in the extracerebral circulation of humans during migraine headache. Ann Neurol 1990, 28:183-187.

40. Crawford MJ, Lehman L, Slater S, Kabbouche MA, LeCates SL, Segers A, Manning P, Powers SW, Hershey AD: Menstrual migraine in adolescents. Headache 2009, 49:341-347.

41. Blume HK, Brockman LN, Breuner CC: Biofeedback therapy for pediatric headache: factors associated with response. Headache 2012 52:1377-1386

42. Varkey E, Cider A, Carlsson J, Linde M: Exercise as migraine prophylaxis: a randomized study using relaxation and topiramate as controls. Cephalalgia 2011, 31:1428-1438.

43. Evans RW: A rational approach to the management of chronic migraine. Headache 2013, 53:168-176. 
44. Bromberg J, Wood ME, Black RA, Surette DA, Zacharoff KL, Chiauzzi EJ: A randomized trial of a web-based intervention to improve migraine selfmanagement and coping. Headache 2012, 52:244-261.

45. Lewis DW, Kellstein D, Dahl G, Burke B, Frank LM, Toor S, Northam RS, White LW, Lawson L: Children's ibuprofen suspension for the acute treatment of pediatric migraine. Headache 2002, 42:780-786.

46. Hamalainen ML, Hoppu K, Valkeila E, Santavuori P: Ibuprofen or acetaminophen for the acute treatment of migraine in children: a double-blind, randomized, placebo-controlled, crossover study. Neurology 1997, 48:103-107.

47. Ahonen K, Hamalainen ML, Rantala H, Hoppu K: Nasal sumatriptan is effective in treatment of migraine attacks in children: A randomized trial. Neurology 2004, 62:883-887.

48. Winner P, Rothner AD, Saper J, Nett R, Asgharnejad M, Laurenza A, Austin R, Peykamian M: A randomized, double-blind, placebo-controlled study of sumatriptan nasal spray in the treatment of acute migraine in adolescents. Pediatrics 2000, 106:989-997.

49. Lewis DW, Winner P, Hershey AD, Wasiewski WW: Efficacy of zolmitriptan nasal spray in adolescent migraine. Pediatrics 2007, 120:390-396.

50. Linder SL, Mathew NT, Cady RK, Finlayson G, Ishkanian G, Lewis DW: Efficacy and tolerability of almotriptan in adolescents: a randomized, double-blind, placebo-controlled trial. Headache 2008, 48:1326-1336.

51. Ahonen K, Hamalainen ML, Eerola M, Hoppu K: A randomized trial of rizatriptan in migraine attacks in children. Neurology 2006, 67:1135-1140.

52. Saper JR, Silberstein S: Pharmacology of dihydroergotamine and evidence for efficacy and safety in migraine. Headache 2006, 46(Suppl 4):S171-S181.

53. Trottier ED, Bailey B, Lucas N, Lortie A: Prochlorperazine in children with migraine: a look at its effectiveness and rate of akathisia. Am J Emerg Med 2012, 30:456-463.

54. Bigal ME, Serrano D, Buse D, Scher A, Stewart WF, Lipton RB: Acute migraine medications and evolution from episodic to chronic migraine: a longitudinal population-based study. Headache 2008, 48:1157-1168.

55. Dodick D, Freitag F: Evidence-based understanding of medicationoveruse headache: clinical implications. Headache 2006 46(Suppl 4):S202-S211.

56. Hershey AD: Current approaches to the diagnosis and management of pediatric migraine. Lancet Neurol 2010, 9:190-204.

57. Lakshmi CV, Singhi $P$, Malhi $P$, Ray M: Topiramate in the prophylaxis of pediatric migraine: a double-blind placebo-controlled trial. J Child Neurol 2007, 22:829-835.

58. Lewis D, Winner P, Saper J, Ness S, Polverejan E, Wang S, Kurland CL, Nye J, Yuen E, Eerdekens M, Ford L: Randomized, double-blind, placebocontrolled study to evaluate the efficacy and safety of topiramate for migraine prevention in pediatric subjects 12 to 17 years of age. Pediatrics 2009, 123:924-934.

59. Sheridan DC, Meckler GD, Spiro DM, Koch TK, Hansen ML: Diagnostic testing and treatment of pediatric headache in the emergency department. J Pediatr 2013, 163:1634-1637.

60. Lewis D, Paradiso E: A double-blind, dose comparison study of topiramate for prophylaxis of basilar-type migraine in children: a pilot study. Headache 2007, 47:1409-1417.

61. Sorge F, De Simone R, Marano E, Nolano M, Orefice G, Carrieri P: Flunarizine in prophylaxis of childhood migraine. A double-blind, placebocontrolled, crossover study. Cephalalgia 1988, 8:1-6.

62. Hershey AD, Powers SW, Bentti AL, Degrauw TJ: Effectiveness of amitriptyline in the prophylactic management of childhood headaches. Headache 2000, 40:539-549.

63. Lewis DW, Diamond S, Scott D, Jones V: Prophylactic treatment of pediatric migraine. Headache 2004, 44:230-237.

64. Apostol G, Pakalnis A, Laforet GA, Robieson WZ, Olson E, Abi-Saab WM, Saltarelli M: Safety and tolerability of divalproex sodium extended-release in the prophylaxis of migraine headaches: results of an open-label extension trial in adolescents. Headache 2009, 49:36-44.

65. Apostol G, Lewis DW, Laforet GA, Robieson WZ, Fugate JM, Abi-Saab WM, Saltarelli MD: Divalproex sodium extended-release for the prophylaxis of migraine headache in adolescents: results of a stand-alone, long-term open-label safety study. Headache 2009, 49:45-53.

66. Taubman B: Clinical trial of the treatment of colic by modification of parent-infant interaction. Pediatrics 1984, 74:998-1003.

67. McKenzie S: Troublesome crying in infants: effect of advice to reduce stimulation. Arch Dis Child 1991, 66:1416-1420.
68. Hikita T, Kodama H, Kaneko S, Amakata K, Ogita K, Mochizuki D, Kaga F, Nakamoto N, Fujii Y, Kikuchi A: Sumatriptan as a treatment for cyclic vomiting syndrome: a clinical trial. Cephalalgia 2011, 31:504-507.

69. Mortimer MJ, Kay J, Jaron A: Clinical epidemiology of childhood abdominal migraine in an urban general practice. Dev Med Child Neurol 1993, 35:243-248.

70. Jernigan SA, Ware LM: Reversible quantitative EEG changes in a case of cyclic vomiting: evidence for migraine equivalent. Dev Med Child Neurol 1991, 33:80-85.

71. Jan MM, Al-Buhairi AR: Is infantile colic a migraine-related phenomenon? Clin Pediatr 2001, 40:295-297.

72. Romanello S, Spiri D, Marcuzzi E, Zanin A, Boizeau P, Riviere S, Vizeneux A, Moretti R, Carbajal R, Mercier JC, Wood C, Zuccotti GV, Crichiutti G, Alberti C, Titomanlio L: Association between childhood migraine and history of infantile colic. JAMA 2013, 309:1607-1612.

73. Titomanlio L, Bargui F, Gibertini GG, Siriez JY, Mercier JC: Quest for the diagnosis. Case 2: A child with abnormal ocular movements. Acta Paediatr 2007, 96:1097-1098.

74. Carson L, Lewis D, Tsou M, McGuire E, Surran B, Miller C, Vu TA: Abdominal migraine: an under-diagnosed cause of recurrent abdominal pain in children. Headache 2011, 51:707-712.

75. Cuomo-Granston A, Drummond PD: Migraine and motion sickness: what is the link? Prog Neurobiol 2010, 91:300-312.

76. Prakash S, Shah ND, Dholakia SY: Recurrent limb pain and migraine: case reports and a clinical review. Cephalalgia 2009, 29:898-905.

77. Arruda MA, Guidetti V, Galli F, Albuquerque RC, Bigal ME: Childhood periodic syndromes: a population-based study. Pediatr Neurol 2010, 43:420-424.

78. Rosman NP, Douglass LM, Sharif UM, Paolini J: The neurology of benign paroxysmal torticollis of infancy: report of 10 new cases and review of the literature. J Child Neurol 2009, 24:155-160.

79. Krams B, Echenne B, Leydet J, Rivier F, Roubertie A: Benign paroxysmal vertigo of childhood: long-term outcome. Cephalalgia 2011, 31:439-443.

80. Gelfand AA, Thomas KC, Goadsby PJ: Before the headache: infant colic as an early life expression of migraine. Neurology 2012, 79:1392-1396.

81. Cuenca-Leon E, Corominas R, Fernandez-Castillo N, Volpini V, Del Toro M, Roig M, Macaya A, Cormand B: Genetic analysis of 27 Spanish patients with hemiplegic migraine, basilar-type migraine and childhood periodic syndromes. Cephalalgia 2008, 28:1039-1047.

82. Wessel MA, Cobb JC, Jackson EB, Harris GS Jr, Detwiler AC: Paroxysmal fussing in infancy, sometimes called colic. Pediatrics 1954, 14:421-435.

83. Castro-Rodriguez JA, Stern DA, Halonen M, Wright AL, Holberg CJ, Taussig LM, Martinez FD: Relation between infantile colic and asthma/atopy: a prospective study in an unselected population. Pediatrics 2001, 108:878-882.

84. Lucassen PL, Assendelft WJ, Van Eijk JT, Gubbels JW, Douwes AC, Van Geldrop WJ: Systematic review of the occurrence of infantile colic in the community. Arch Dis Child 2001, 84:398-403.

85. Giffin NJ, Benton S, Goadsby PJ: Benign paroxysmal torticollis of infancy: four new cases and linkage to CACNA1A mutation. Dev Med Child Neurol 2002, 44:490-493.

86. Basser LS: Benign Paroxysmal Vertigo of Childhood. (a Variety of Vestibular Neuronitis). Brain 1964, 87:141-152.

87. Drigo P, Carli G, Laverda AM: Benign paroxysmal vertigo of childhood. Brain Dev 2001, 23:38-41.

88. Lindskog $U$, Odkvist L, Noaksson L, Wallquist J: Benign paroxysmal vertigo in childhood: a long-term follow-up. Headache 1999, 39:33-37.

89. Marcelli V, Piazza F, Pisani F, Marciano E: Neuro-otological features of benign paroxysmal vertigo and benign paroxysmal positioning vertigo in children: a follow-up study. Brain Dev 2006, 28:80-84

90. Lanzi G, Balottin U, Fazzi E, Tagliasacchi M, Manfrin M, Mira E: Benign paroxysmal vertigo of childhood: a long-term follow-up. Cephalalgia 1994, 14:458-460.

91. Li BU, Balint JP: Cyclic vomiting syndrome: evolution in our understanding of a brain-gut disorder. Adv Pediatr 2000, 47:117-160.

92. Li BU, Lefevre F, Chelimsky GG, Boles RG, Nelson SP, Lewis DW, Linder SL, Issenman RM, Rudolph CD: North American Society for Pediatric Gastroenterology, Hepatology, and Nutrition consensus statement on the diagnosis and management of cyclic vomiting syndrome. J Pediatr Gastroenterol Nutr 2008, 47:379-393.

93. Prakash C, Staiano A, Rothbaum RJ, Clouse RE: Similarities in cyclic vomiting syndrome across age groups. Am J Gastroenterol 2001, 96:684-688. 
94. Li BU, Misiewicz L: Cyclic vomiting syndrome: a brain-gut disorder. Gastroenterol Clin North Am 2003, 32:997-1019.

95. Abu-Arafeh I, Russell G: Prevalence and clinical features of abdominal migraine compared with those of migraine headache. Arch Dis Child 1995, 72:413-417.

96. Tan V, Sahami AR, Peebles R, Shaw RJ: Abdominal migraine and treatment with intravenous valproic Acid. Psychosomatics 2006, 47:353-355

97. Russell G, Abu-Arafeh I, Symon DN: Abdominal migraine: evidence for existence and treatment options. Pediatric drugs 2002, 4:1-8.

98. Weydert JA, Ball TM, Davis MF: Systematic review of treatments for recurrent abdominal pain. Pediatrics 2003, 111:e1-e11.

99. Engel MA, Becker C, Reeh PW, Neurath MF: Role of sensory neurons in colitis: increasing evidence for a neuroimmune link in the gut. Inflamm Bowel Dis 2011, 17:1030-1033.

100. Epstein LG, Zee PC: Infantile colic and migraine. JAMA 2013, 309:1636-1637.

101. Abell TL, Adams KA, Boles RG, Bousvaros A, Chong SK, Fleisher DR, Hasler WL, Hyman PE, Issenman RM, Li BU, Linder SL, Mayer EA, McCallum RW, Olden K, Parkman HP, Rudolph CD, Tache Y, Tarbell S, Vakil N: Cyclic vomiting syndrome in adults. Neurogastroenterol Motil 2008, 20:269-284.

102. Tache Y: Cyclic vomiting syndrome: the corticotropin-releasing-factor hypothesis. Dig Dis Sci 1999, 44:79S-86S.

103. Sanger GJ, Andrews PL: Treatment of nausea and vomiting: gaps in our knowledge. Auton Neurosci 2006, 129:3-16.

104. Dale RC, Gardiner A, Antony J, Houlden H: Familial PRRT2 mutation with heterogeneous paroxysmal disorders including paroxysmal torticollis and hemiplegic migraine. Dev Med Child Neurol 2012, 54:958-960.

105. John B, Klemm E, Haverkamp F: Evidence for altered basal ganglia and cortical functions in transient idiopathic dystonia. J Child Neurol 2000, 15:820-822

106. Kakisaka Y, Wakusawa K, Haginoya K, Saito A, Uematsu M, Yokoyama H, Sato T, Tsuchiya S: Efficacy of sumatriptan in two pediatric cases with abdominal pain-related functional gastrointestinal disorders: does the mechanism overlap that of migraine? J Child Neurol 2010, 25:234-237.

107. Kothare SV: Efficacy of flunarizine in the prophylaxis of cyclical vomiting syndrome and abdominal migraine. Eur J Paediatr Neurol 2005, 9:23-26.

108. Lima MM, Padula NA, Santos LC, Oliveira LD, Agapejev S, Padovani C: Critical analysis of the international classification of headache disorders diagnostic criteria (ICHD I-1988) and (ICHD II-2004), for migraine in children and adolescents. Cephalalgia 2005, 25:1042-1047.

109. Holstein BE, Andersen A, Krolner R, Due P, Hansen EH: Young adolescents' use of medicine for headache: sources of supply, availability and accessibility at home. Pharmacoepidemiol Drug Saf 2008, 17:406-410.

110. Andersen A, Holstein BE, Due P, Hansen EH: Medicine use for headache in adolescence predicts medicine use for headache in young adulthood. Pharmacoepidemiol Drug Saf 2009, 18:619-623.

111. Weir GA, Cader MZ: New directions in migraine. BMC Med 2011, 9:116.

112. Eising E, De Vries B, Ferrari MD, Terwindt GM, van den Maagdenberg AM: Pearls and pitfalls in genetic studies of migraine. Cephalalgia 2013, 33:614-625

113. Di Lorenzo C, Grieco GS, Santorelli FM: Migraine headache: a review of the molecular genetics of a common disorder. J Headache Pain 2012, 13:571-580

114. Eising E, A Datson N, Van Den Maagdenberg AM, Ferrari MD: Epigenetic mechanisms in migraine: a promising avenue? BMC Med 2013, 11:26.

115. Lanzi G, Zambrino CA, Ferrari-Ginevra O, Termine C, D'Arrigo S, Vercelli P, De Silvestri A, Guglielmino CR: Personality traits in childhood and adolescent headache. Cephalalgia 2001, 21:53-60.

116. Strine TW, Okoro CA, McGuire LC, Balluz LS: The associations among childhood headaches, emotional and behavioral difficulties, and health care use. Pediatrics 2006, 117:1728-1735.

117. Smith MS, Martin-Herz SP, Womack WM, Marsigan JL: Comparative study of anxiety, depression, somatization, functional disability, and illness attribution in adolescents with chronic fatigue or migraine. Pediatrics 2003, 111:e376-e381.

118. Milde-Busch A, Boneberger A, Heinrich S, Thomas S, Kuhnlein A, Radon K, Straube A, Von Kries R: Higher prevalence of psychopathological symptoms in adolescents with headache. A population-based crosssectional study. Headache 2010, 50:738-748.
119. Pogliani L, Spiri D, Penagini F, Nello FD, Duca P, Zuccotti GV: Headache in children and adolescents aged 6-18 years in northern Italy: prevalence and risk factors. Eur J Paediatr Neurol 2011, 15:234-240.

120. Margari F, Lucarelli E, Craig F, Petruzzelli MG, Lecce PA, Margari L: Psychopathology in children and adolescents with primary headaches: Categorical and dimensional approaches. Cephalalgia 2013, 33:1311-1318.

121. Hershey AD, Powers SW, Vockell AL, LeCates S, Kabbouche MA, Maynard MK: PedMIDAS: development of a questionnaire to assess disability of migraines in children. Neurology 2001, 57:2034-2039.

doi:10.1186/s13052-014-0092-4

Cite this article as: Spiri et al:: Pediatric migraine and episodic syndromes that may be associated with migraine. Italian Journal of Pediatrics 2014 40:92.

\section{Submit your next manuscript to BioMed Central and take full advantage of:}

- Convenient online submission

- Thorough peer review

- No space constraints or color figure charges

- Immediate publication on acceptance

- Inclusion in PubMed, CAS, Scopus and Google Scholar

- Research which is freely available for redistribution

Submit your manuscript at www.biomedcentral.com/submit
C BioMed Central 